RESEARCH ETHICS

\title{
Paying research participants: a study of current practices in Australia
}

\author{
C L Fry, A Ritter, S Baldwin, K J Bowen, P Gardiner, T Holt, R Jenkinson, J Johnston
}

J Med Ethics 2005;31:542-547. doi: 10.1136/jme.2004.009290

See end of article for authors' affiliations

...................

Correspondence to: C Fry, Senior Research Fellow, Turning Point Alcohol and Drug Centre Inc., 54-62 Gertrude St, Melbourne VIC 3065, Australia; craig.fry@ turningpoint.org.au

Received 6 May 2004 In revised form 23 November 2004 Accepted for publication 26 November 2004
Objective: To examine current research payment practices and to inform development of clearer guidelines for researchers and ethics committees.

Design: Exploratory email based questionnaire study of current research participant reimbursement practices. A diverse sample of organisations and individuals were targeted.

Setting: Australia.

Participants: Contacts in 84 key research organisations and select electronic listservers across Australia. A total of 100 completed questionnaires were received with representations from a variety of research areas (for example, market, alcohol and drug, medical, pharmaceutical and social research).

Main measurements: Open-ended and fixed alternative questions about type of research agency; type of research; type of population under study; whether payment is standard; amounts and mechanisms of payment; factors taken into account when deciding on payment practices; and whether payment policies exist.

Results: Reimbursement practice is highly variable. Where it occurs (most commonly for drug dependent rather than health professional or general population samples) it is largely monetary and is for time and out-of-pocket expenses. Ethics committees were reported to be often involved in decision making around reimbursement.

Conclusions: Research subject payment practices vary in Australia. Researchers who do provide payments to research participants generally do so without written policy and procedures. Ethics committees have an important role in developing guidelines in this area. Specific guidelines are needed considering existing local policies and procedures; payment models and their application in diverse settings; case study examples of types and levels of reimbursement; applied definitions of incentive and inducement; and the rationale for diverse payment practices in different settings.
A midst increasing public interest and scrutiny of research one issue attracting growing attention is the question of whether payments to research participants are ethical. Anecdotally, there appear to be diverse practices across disciplines for paying research participants. In Australia, it has been common practice since the mid-1980s for researchers to pay alcohol and drug users who participate in research interviews and has proved a successful way of recruiting "hidden" groups of illicit drug users for a multitude of studies. ${ }^{1}$ Research participant payments also appear to be standard in alcohol and drug research in the USA ${ }^{2}$ and relatively common in the UK. ${ }^{3}$

Outside of alcohol and drug research, practices seem to depend on the research setting and target group, the availability of funds, and what is accepted practice within particular disciplines and the ethics committees that oversee the research. ${ }^{4-6}$ For example, in health services research the provision of monetary payments or other incentives is a method commonly employed to achieve high response rates in mail-out and other direct contact surveys targeting health professionals (for example, general practitioners). Indeed, payments are seen as a necessary way of ensuring an adequate response rate from busy professionals and therefore as a way of ensuring the validity of the research..$^{7-9}$ Dickert and Grady ${ }^{10}$ have recently noted that patients are frequently paid to participate in clinical research, despite the misconception in the literature that only healthy subjects are paid.

According to existing guidelines, the major ethical concern raised by research participant payment is its possible adverse impact on voluntary consent. Current National Health and Medical Research Council (NHMRC) guidelines for ethical conduct in research involving humans in Australia specify that "the consent of a person to participate in research must not be subject to any coercion or to any inducement or influence which could impair its voluntary character" (p. 12). ${ }^{11}$ Further, the main danger of inducements is that they may make it "more difficult for participants to assess the risks and benefits of research, encouraging them to expose themselves to risk of harm" (p. C9). ${ }^{12}$ Similar recommendations are found in guidelines from other international bodies. ${ }^{13-16}$ These encourage ethics committees and researchers to reflect on the possible justification for payments in determining if they are ethically permissible or not.

In practice, judging when research participant payments constitute undue inducement and when they are fair recognition is complicated. For one individual, a particular mode or amount of payment may be sufficient to cloud judgement regarding involvement in research, whereas for others payment may not affect their decision. Such judgements are not made any easier by the lack of clear and often conflicting guidelines. ${ }^{4}{ }^{10}$ Policies and procedures do exist in different research institutions, however, they are rarely disseminated beyond the settings in which they were developed.

A small number of studies have analysed payment practice and policy in the USA. Latterman and Merz's review of biomedical and psychosocial studies published during 1997-98 showed that payments varied widely according to participant group and study demands. ${ }^{5}$ A recent study of 32 US research organisations found that although most organisations pay some research participants, most $(63 \%)$ did not have written guidelines for this. The study also showed that 
both investigators and institutional review boards were involved in making payment decisions, however with little specific guidance available, standards varied. ${ }^{6}$ Weise and colleagues' study of payment practices in paediatric research also showed that payment was permitted in most (66\%) responding institutions, and that practices varied widely due in part to conflicting guidance from federal and expert paediatric sources. ${ }^{4}$

To date there has been no equivalent research in Australia. In this setting, human research ethics policies share a common history with the USA-anchored in the principles of biomedical ethics ${ }^{17}$ - but the environment is generally less regulated than in the USA. Further empirical investigation of payment practices and researcher attitudes about these (particularly in jurisdictions outside the USA) will help to shed light on this important issue. Such data have the potential to support ethics committee decision making processes and build their capacity to offer clearer guidance to researchers uncertain about the ethical limits of participant payment. The purpose of the current paper therefore is to report on the findings of an exploratory study of current research participant reimbursement practices in Australia. The variables of interest were the extent to which reimbursement was standard practice, by what mechanism and what quanta, and whether local written guidelines or policies exist that could be instructive for a broader audience.

\section{METHOD}

We developed a brief structured questionnaire with reference to categorisations of research types and methods, target groups, research organisations, other relevant variables of interest derived from recent published studies on research payment practices, ${ }^{4-9}$ and research categories defined in the Australian NHMRC research ethics guidelines. ${ }^{11} \mathrm{~A}$ draft questionnaire was pilot tested with five independent researchers to assess ease of completion and clarity of questions. After revision the final questionnaire contained open-ended and fixed alternative questions about type of research organisation, type of research, population under study, whether payment is standard, amounts and mechanisms of payment, and factors taken into account when deciding on payment practices.

Through a team consensus process, research organisation categories were developed to form the sample frame for the study. These included: university, hospital, research institute/ centre, pharmaceutical company, and market research organisation. Organisation contacts were identified through Australian university websites and general internet searches, and the criterion for selection was current direct involvement in the conduct of research with human participants. Through purposive sampling $^{18}$ a diverse sample of 70 organisations was targeted in order to capture a diverse range of current research practices and policies. In addition to sending the questionnaire direct to key contacts from each organisation (89 individuals identified), the study team also employed convenience sampling ${ }^{18}$ via select electronic listservers to distribute the questionnaire in order to further broaden the sample (that is, Public Health Association of Australia (PHAA); Alcohol and other Drugs Council of Australia (ADCA Update); Australian Resource Centre for Hospital Innovations (ARCHI); Oz Hep Info). We distributed the questionnaire via email, along with a plain language statement outlining the rationale for the study. The Turning Point Alcohol and Drug Centre Ethics Facilitation Committee gave ethical approval for the study.

Participants were initially given one week to return the questionnaire by mail, fax, or email. Ten days after the initial email communication, we distributed a follow up email to all individuals and the four listservers selected to encourage responses prior to the deadline. Returned questionnaires were accepted for a period of two and a half weeks. A total of 100 completed questionnaires were returned (79 via email, 9 via post, and 12 via facsimile). Twenty one responses were received from the 89 individual contacts at the targeted research organisations (an indicative response rate of $24 \%$ ), 63 responses from the selected listserver postings ( 35 from PHAA, 25 from ADCA Update, 3 from Oz Hep Info) and 16 responses from anonymous individuals (indicative response rate increases to $42 \%$ if we assume anonymous responses came from the group of 89 individual contacts). Although an overall response rate cannot be calculated due to the mixed sampling methods employed, the sample of respondents was diverse and covered a range of research organisational types, research target groups, and research methods. We deidentified the questionnaires to protect confidentiality and these were entered into an SPSS database for statistical analysis. We analysed the responses descriptively.

\section{RESULTS}

Table I summarises the sample characteristics along with the key variables of interest - the degree to which reimbursement is standard practice ("Is the reimbursement, via any means or types, of research participants standard in the research that you conduct?"), the proportion of projects that reimburse participants ("What percentage, approximately, of your research projects reimburse the participants?"), and the median monetary amounts ("If monetary reimbursement is provided, how much would a participant receive for taking part in a typical research project undertaken by you?"). Results are presented according to organisational setting, research target group, and research method.

Reimbursement via any means was standard practice for around one third (34\%) of the respondents, and not standard for just over half $(54 \%)$. The remaining $12 \%$ of respondents indicated that practices differed according to factors such as research type, demand characteristics, and the target group. Examination of organisation type, research target group, and research method revealed no clear pattern to payment practices (see table 1 ).

Organisations that reimburse more than $50 \%$ of the time included government and universities. Research target groups that were more commonly reimbursed than not, were drug dependent participants, Aboriginal and Torres Strait Islander (ATSI), and general population samples. Respondents who engaged in the research methods of epidemiology, clinical research, market research, and social research more commonly reported participant reimbursements.

Where reimbursements were provided at all, the median monetary amount varied between AUD\$15.00 and AUD $\$ 200.00$ (see table 1) ( 1 AUD = GBP 0.40, USD 0.72 and EUR 0.58). At the top end of payment was the pharmaceutical company surveyed, the target groups of patients and health professionals, and evaluation research. However, for some target groups (for example, drug dependent, ATSI, children) there appeared to be an inverse relation between reimbursement likelihood and amount, in contrast with those reported for health professionals and patients (where proportionally fewer studies reimburse, but at a higher amount).

Common reasons offered by respondents $(n=67)$ in cases where reimbursements are not provided to participants included: that it was unnecessary $(46 \%)$; that reimbursements are inducements (33\%); and that the practice may compromise participant willingness to consider the risks and benefits of being involved in the research $(22 \%)$. A quarter of respondents noted that reimbursement can potentially target economically vulnerable people and may compromise 
Table 1 Reimbursement practices (\% where it is standard, percentage of projects that reimburse, and typical amounts provided) by organisation type, main target group, and main research method

\begin{tabular}{|c|c|c|c|c|c|c|}
\hline & \multicolumn{2}{|c|}{$\begin{array}{l}\text { Reimbursement is standard* } \\
(\mathrm{n}=97) \dagger\end{array}$} & \multicolumn{2}{|c|}{$\begin{array}{l}\text { Percentage of projects that } \\
\text { reimburse }(n=64) \ddagger\end{array}$} & \multicolumn{2}{|c|}{$\begin{array}{l}\text { Typical reimbursement amounts } \\
\text { provided (\$AUD) }\end{array}$} \\
\hline & $\mathbf{n}$ & $\%$ & Median & Range & Median & Range \\
\hline \multicolumn{7}{|l|}{ Organisation type§ } \\
\hline Research centre/institute $(n=25)$ & 11 & 44 & 50 & $1-100$ & 22.50 & $5-100$ \\
\hline Hospital $(n=21)$ & 6 & 29 & 50 & $1-100$ & 20.00 & $6-100$ \\
\hline Government $(n=9)$ & 4 & 44 & 100 & $60-100$ & 25.00 & $20-75$ \\
\hline University $(n=37)$ & 12 & 32 & 73 & $5-100$ & 20.00 & $15-110$ \\
\hline Market research $(n=3)$ & - & - & 33 & $1-65$ & 60.00 & - \\
\hline Pharmaceutical company $(n=1)$ & - & - & 25 & - & 200.00 & - \\
\hline \multicolumn{7}{|l|}{ Target group } \\
\hline Drug dependent $(n=19)$ & 12 & 63 & 78 & $20-100$ & 20.00 & $15-100$ \\
\hline Children/youth $(n=11)$ & 4 & 36 & 45 & $1-75$ & 15.00 & $10-20$ \\
\hline Health professionals $(n=6)$ & 1 & 17 & 50 & $30-100$ & 110.00 & - \\
\hline ATSI $(n=5)$ & 2 & 40 & 60 & $5-100$ & 15.00 & $5-25$ \\
\hline Patients $(n=20)$ & 4 & 20 & 23 & $1-100$ & 100.00 & $6-200$ \\
\hline General population $(n=11)$ & 4 & 36 & 75 & $1-100$ & 25.00 & $20-60$ \\
\hline $\operatorname{Mix}(n=25)$ & 6 & 24 & 25 & $5-100$ & 25.00 & $15-110$ \\
\hline \multicolumn{7}{|l|}{ Method $^{* *}$} \\
\hline Mixed (qualitative and quantitative) $(n=37)$ & 11 & 30 & 50 & $1-100$ & 20.00 & 6-75 \\
\hline Epidemiology $(n=17)$ & 6 & 35 & 78 & $10-100$ & 20.00 & $15-30$ \\
\hline Evaluation $(n=7)$ & 2 & 33 & 7 & $2-100$ & 110.00 & $5-110$ \\
\hline Clinical research $(n=32)$ & 11 & 34 & 55 & $1-100$ & 40.00 & $20-200$ \\
\hline Market research $(n=4)$ & 2 & 50 & 63 & $1-90$ & 25.00 & $25-60$ \\
\hline Social research $(n=2)$ & 1 & 50 & 60 & $1-100$ & 20.00 & $20-25$ \\
\hline \multicolumn{7}{|c|}{$\begin{array}{l}\text { *Standard refers to occurring in the majority of projects. } \\
\text { tData missing for three respondents. } \\
\text { †Where reimbursement is provided at all. } \\
\text { \$Data missing for four respondents. } \\
\text {-Data missing for three respondents. } \\
\text { **Data missing for one respondent. } \\
\text { ATSI, Aboriginal and Torres Strait Islander; AUD, Australian dollars. }\end{array}$} \\
\hline
\end{tabular}

scientific integrity by altering the make up of the participant population $(25 \%)$. Smaller numbers reported that in their view reimbursement could result in harm to participants $(3 \%)$ and that they had insufficient funds to cover costs $(6 \%)$. Reasons for reimbursement did not differ as a function of target group.

Of those who reported reimbursement to research participants, the most common types were examined for each main research target group (table 2 ). Money was the commonest reimbursement type offered (64\%) for drug dependent target groups than other specified groups.

The basis of decisions to pay research participants varied. The commonest responses were that the decision was made according to ethics committee advice $(24 \%)$, whether or not the target group was difficult to recruit $(21 \%)$, or if significant participant time and effort would be required (19\%). Less common responses included that it was standard practice to pay participants $(8 \%)$, that reimbursement of direct costs to participants was necessary (15\%), and that it was dependent on available funds ( $12 \%)$. Determination on a case-by-case basis was noted by $10 \%$ of respondents. A small number $(5 \%)$ indicated that reimbursement practice depended upon the likely impact on response rate, or in cases of collection of sensitive information. The rationale for providing reimbursement to research participants was most commonly found to be for time $(73 \%)$, for travel expenses $(64 \%)$, for inconvenience $(54 \%)$, as an inducement or incentive $(47 \%)$, for information provided $(24 \%)$, and as a way of indicating appreciation out of respect (9\%).

Of interest was that the majority of survey respondents $(\mathrm{n}=71,72 \%)$ reported that no written guidelines or policy and procedures concerning the reimbursement of research participants existed in their place of research. The $18 \%$ who reported that policy did exist were researchers in the

Table 2 Most common mechanisms of reimbursement offered as a function of main research target group $(n=75)$

\begin{tabular}{|c|c|c|c|c|c|}
\hline Target group & $\begin{array}{l}\text { Money } \\
\text { (n) }\end{array}$ & $\begin{array}{l}\text { Voucher* } \\
\text { (n) }\end{array}$ & $\begin{array}{l}\text { Food/refreshments } \\
\text { (n) }\end{array}$ & $\begin{array}{l}\text { Travel costs } \\
\text { (n) }\end{array}$ & $\begin{array}{l}\text { Miscellaneous } \dagger \\
\text { (n) }\end{array}$ \\
\hline Drug dependent & 15 & 1 & 0 & 0 & 0 \\
\hline Children/youth & 4 & 2 & 0 & 0 & 1 \\
\hline Health professionals & 2 & 0 & 0 & 0 & 2 \\
\hline ATSI & 2 & 1 & 0 & 0 & 1 \\
\hline Patients & 5 & 1 & 1 & 2 & 4 \\
\hline General population & 6 & 1 & 0 & 1 & 1 \\
\hline Mix & 14 & 2 & 4 & 0 & 2 \\
\hline Total sample & 48 & 8 & 5 & 3 & 11 \\
\hline
\end{tabular}


university, research centre/institute or hospital settings. It is unclear from the data what the form and content of these written policies are.

Just under a third of the respondents (29\%) indicated that their research reimbursement practices had previously been questioned by an ethics committee. The commonest issue raised in these cases was the potential for inducement and undermining of voluntary consent $(50 \%)$. Other reported ethics committee queries concerned issues such as risks and harms, possible negative uses of cash payments by participants, and sample biases. Respondents also indicated that in most cases, research proposals were approved eventually following negotiations and discussions with the ethics committees.

\section{DISCUSSION}

We have endeavoured to provide a preliminary analysis of research payment practices across a variety of research settings, samples, and methods in the Australian setting. Although few consistent patterns emerge from the current findings, a number of interesting issues are worthy of discussion.

\section{Reimbursements, research target groups, and vulnerability}

Most respondents reported they had previously provided reimbursements to research participants, yet this was not a standard practice for most respondents, and consistent with previous studies conducted in the USA, ${ }^{4-6}$ reported practices and quanta varied widely. Practice was also not distinguished by type of organisation or as a function of the research methodology commonly employed by respondents.

In relation to target group, our findings suggest it is more common for drug dependent research participants to be paid than general population samples, patients, or health professionals. Further, there exists an apparent inverse relation between reimbursement likelihood and amount, where some target groups (for example, drug dependent, ATSI, children) are reimbursed more often than others examined (health professionals, patients) but at lower levels. This is possibly due to varying discipline standards where it is accepted practice for some groups to be paid more commonly than others, ${ }^{23}$ or differing levels of ethics committee comfort around payment amounts offered to more "vulnerable" research participants (see references 19-21 for examples in relation to research on illicit drug use).

In the payment ethics literature "vulnerability" is commonly discussed in relation to patients as research participants, where "the special vulnerability of patients is most often attributed to ... the inability of patients to distinguish clinical care from research ... and a perceived difference in power between patients and investigators, especially when an investigator is both the clinician and the researcher". ${ }^{10}$ In refuting the notion of "special vulnerability", Dickert and Grady claim that there is no inherent reason for treating patients and healthy research participants differently when it comes to research payments ${ }^{10}$ and argue for a standardised approach to payment across studies. Others suggest that differences between participant groups (in terms of not only vulnerabilities but also interests and reasons for research participation) should be considered in determining payment guidelines and policies. ${ }^{22}$

The question of whether different research target groups are inherently more vulnerable than others is beyond the scope of this paper. However, our finding that patient groups (when paid) may receive on average larger amounts than the other target groups suggests that in some instances the issue of vulnerability may be less important next to the other "situational" factors such as the expected level of difficulty in recruiting particular target groups, and the demand characteristics and requirements of participation (for example, associated costs and inconveniences, time required). From the researcher's perspective, the desire to enhance recruitment rates by reimbursing participants for time and effort (common justifications reported in this study) in certain instances may be reason enough to vary the frequency, type, and quanta of payments in research seeking to recruit difficult to access groups. In this way the standardisation of research payments across studies that some have advocated ${ }^{10}$ may not be feasible.

\section{Ethics and reimbursement}

Our findings suggest some interesting points about the basis of decision making on participant payment ethics, which could inform development of guidelines on this issue. The rationale for reimbursement was largely identified as paying participants for out-of-pocket expenses and recognition for contribution, although a large minority identified the provision of inducement or incentive as a reason for payment. Conversely, where reimbursements were not provided, the commonest reason given was that it was unnecessary or reflected an inducement. Findings such as these which reflect divergent views on the question of payment and consent are perhaps unsurprising given previous commentary around the lack of clear and often conflicting guidelines on the participant payment question. ${ }^{4}{ }^{10}$ However, the results also raise concerns about how researchers and ethics committees interpret the boundaries of incentive and inducement when making decisions about participant payment ethics, and what this might mean for expectations of consistent ethics committee decisions on this question. It seems there are three possible stances one can take:

- payments are a fair reimbursement for participant contribution, effort, and expenses incurred

- payments represent undue influence on choice to participate thereby undermining voluntariness

- payments serve as a fair influence on a participant's choice to engage in research and do not undermine voluntariness.

We have begun to examine this third possibility in detail elsewhere as it relates to individual motivations for research participation and applied meanings of voluntary consent. ${ }^{19-21}$ Further empirical research is necessary to identify the manner in which ethics committees and researchers make decisions about participant payment practices.

Our study highlights an important future role for ethics committees in guidelines development in Australia. A quarter of respondents indicated that ethics committee advice informs their own decisions on whether or not participants are reimbursed in specific projects, and just under a third of respondents reported that their payment practices had been queried by ethics committees. Further, the finding that most respondents did not have access to written guidelines on research participant reimbursement practices was consistent with the findings of previous studies ${ }^{6}{ }^{10}$ and highlights the current gap in applied information concerning research payment ethics in Australia.

\section{Limitations of the study}

The primary limitation of our study is its preliminary nature. Time and resource limits restricted the choice of sampling method and therefore population coverage. Although the combined purposive and convenience sampling achieved a diverse group of respondents, and enabled response saturation on the variables of interest, there were shortfalls in this approach which raise questions about the generalisability of the findings. Quota sampling ${ }^{18}$ could have ensured larger 
numbers of responses were obtained for the different research organisation categories studied (particularly those for which relatively fewer responses were obtained such as government, market research, and pharmaceutical company categories). This may have allowed us to further explore any between-organisation payment practice differences, and to minimise selection biases in the current sample through inclusion of additional categories of the "research organisation" population (or indeed "target groups") not covered thereby enhancing sample representativeness.

Another limitation was that categorisations of research types and methods were difficult to obtain due to the fact that mixed methods approaches seemed to be the norm. Further, the question format did not allow for partitioning of within-organisation payment practice variability by population types or research methods. Even though participants were asked to provide responses with reference to their own current research, researchers who completed the questionnaire may have been responding across a broad range of research types and target groups. Payment practice was not distinguished by type of organisation or research methodology in this study; however, in the light of the data collection limits identified in the current study this possibility should not be discounted. In noting the varying discipline standards in payment practices previously reported, ${ }^{2459}$ future studies should endeavour to examine more closely the potential interaction between organisation type, target group, and research methods as a factor in explaining how and why payment practices differ.

\section{Future directions}

Due to limited resources, we were unable to collect and analyse existing written policies on participant payment (identified by $18 \%$ of respondents). Future research could undertake a review of payment policies that exist in the Australian context and compare this with work already conducted in the USA. ${ }^{4}{ }^{6}$ It is worth noting though that these US studies have also shown that written policies and procedures are not the norm for the majority of research organisations where payments are offered. Existing policy documents will be an important source of information, however additional empirical data to identify practices not governed by local policy will be needed to inform development of payment guidelines that cover a variety of disciplines and settings. From here, this study could be replicated and expanded, including review of the questionnaire, engaging in quota sampling or perhaps a random sample of known research organisations, and determining a priori hypotheses to drive the statistical analyses. For example, future research might further explore the relation between payment frequency, amount, and target group vulnerability, and whether having written guidelines/policies improves ethics committee approval rates of proposed payment to participants.

In the meantime, the bioethics literature contains a number of examples of payment models ${ }^{102-24}$ that could be adapted to guide participant payment practices in Australian research. For example, Dickert and Grady discuss three models of payment:

- Market model-monetary payments are an incentive to achieve adequate recruitment where payment amounts are based on supply and demand.

- Wage-payment model-where participants performing similar functions are paid similar amounts and payment is standardised against unskilled working wage equivalencies.

- Reimbursement model-where variable payments are provided to reimburse for expenses incurred by individual participants.
To our knowledge these and other similar models proposed have not been validated in different research settings (beyond clinical research) or for different respondent groups, or against empirical data on the reasons why people participate in research.

\section{Concluding remarks}

It is beyond the scope of this piece to evaluate the available models of payment comprehensively. However, that the current study findings indicate at least preliminary evidence of acceptance in the Australian research community (at least among those researchers who responded to our questionnaire) of key elements from some models is worth noting. For example, the commonest justifications for payment reported in this study (that is, for time, travel expenses, inconvenience and information provided, or as an incentive) indicate support for Dickert and Grady's market and reimbursement models, and they perhaps also help to explain the observed variability in practices and, again, suggest a reason why standardisation of payments across studies may not be achievable. Further research should be undertaken to determine the applied validity of these models in the Australian setting.

In summary, this exploratory study has shown that research payment practices vary in Australia, and that researchers who do provide payments to research participants generally do so without written policy and procedures. Our main conclusion is that clearer guidelines are needed in this area and that ethics committees have an important role in supporting the development of such resources. In Australia, the principal advisory committee to the NHMRC on health and medical research ethics-the Australian Health Ethics Committee-in its current 2003-05 triennium is undertaking a consultative review of the NHMRC national statement of ethical conduct in research involving humans. ${ }^{11}$ This presents a timely opportunity to address the need for research payment ethics guidelines in Australia, and this work could also inform practice in other countries.

Based on the findings of this study and building on Ackerman's earlier suggestions, ${ }^{23}$ we recommend that specific guidelines on research payment ethics could usefully consider:

- a review of existing local policies and procedures

- available payment models and their application in diverse settings

- case study examples of appropriate types and levels of reimbursement

- applied definitions of incentive and inducement that take account of various motivations people may have for research participation and situational demands of recruiting difficult to access target groups

- the rationale for diverse payment practices in different settings.

As Dickert and colleagues ${ }^{6}$ have noted, "mere convergence does not make standards ethical, nor does variation imply a problem" (p. 373). However, more specific guidance based on the experiences across disciplines and settings can only help to improve decision making by both ethics committees and researchers on the often-difficult question of "When is it ethical to pay research participants?".

\section{ACKNOWLEDGEMENTS}

The authors are grateful to the reviewers A Ballantyne and C Grady for insightful comments and suggestions on the manuscript. 


\section{Authors' affiliations}

C L Fry, Turning Point Alcohol and Drug Centre and Department of Public Health, University of Melbourne, Australia

A Ritter, K J Bowen, P Gardiner, T Holt, R Jenkinson, J Johnston, Turning Point Alcohol and Drug Centre, Australia

S Baldwin, Centre for Harm Reduction, Burnet Institute, Melbourne, Australia

Turning Point Alcohol and Drug Centre funded the conduct of this research. C Fry is supported by the 2003 Australian Museum and Australian Catholic University Eureka Prize for Research in Ethics.

\section{REFERENCES}

1 Fry CL, Hall W. An ethical framework for drug epidemiology: identifying the issues. Bull Narc 2002:54:131-42.

2 College on Problems of Drug Dependence. Human subject issues in drug abuse research. Drug Alcohol Depend 1995;37:167-75.

3 Wright S, Klee H, Reid P. Interviewing illicit drug users: observations from the field. Addict Res 1998;6:517-35.

4 Weise KL, Smith ML, Mascke KJ, et al. National practices regarding payment to research subjects for participating in pediatric research. Pediatrics 2002;110:577-82.

5 Latterman J, Merz JF. How much are subjects paid to participate in research? Am J Bioethics 2001;1:45-6.

6 Dickert N, Emanuel E, Grady C. Paying research subjects: an analysis of current policies. Ann Intern Med 2002;136:368-73.

7 Singer E, Van-Hoewyk J, Maher MP. Does payment of incentives create expectation effects? Public Opin Q 1998;62:152-64.

8 Rudy EB, Estok PJ, Kerr ME, et al. Research incentives: Money versus gifts. Nurs Res 1994:43:253-5.

9 Kasprzyk D, Montano DE, St Lawrence JS, et al. The effects of variations in mode of delivery and monetary incentive on physicians' responses to a mailed survey assessing STD practice patterns. Eval Health Prof 2001;24:3-17.

10 Dickert N, Grady C. What's the price of a research subject? Approaches to payment for research participation. N Engl J Med 1999;341:198-203.
11 National Health and Medical Research Council. National statement of ethical conduct in research involving humans. Canberra: Commonwealth of Australia, 1999, www.health.gov. au/nhmrc/issues/index.htm (accessed 5 March 2003).

12 National Health and Medical Research Council. Human research ethics handbook. Commentary on the national statement on ethical conduct in research involving humans. Canberra: Commonwealth of Australia, 2002.

13 South African Medical Research Council. MRC Guidelines on Ethics for Medical Research, www.mrc.ac.za/ethics/ethicshuman.htm (accessed 4 March 2003).

14 CIOMS. International Ethical Guidelines for Biomedical Research Involving Human Subjects. Geneva: Council for International Organizations of Medical Sciences, World Health Organization, 2002, www.cioms.ch/ guidelines_nov_2002_blurb.htm (accessed 4 March 2003).

15 The National Commission for the Protection of Human Subjects of Biomedical and Behavioral Research. The Belmont report: ethical principles and guidelines for the protection of human subjects of research. Washington, DC: Government Printing Office, 1979. http://ohsr.od.nih.gov/guidelines/ belmont.html (accessed 5 January 2005).

16 The Health Research Council of New Zealand. Guidelines on ethics in health research. Auckland: HRC, 2002. www.hrc.govt.nz/root/Publications/ Ethics_Reports_and_Guidelines.html (accessed 5 January 2005).

17 Beauchamp TL, Childress JF. Principles of Biomedical Ethics, 5th edn. Oxford: Oxford University Press, 2001

18 Sarantakos S. Social Research, 2nd edn. South Yarra: Macmillan Education Australia Pty Ltd., 1998.

19 Fry C, Dwyer R. For love or money? An exploratory study of why injecting drug users participate in research. Addiction 2001;96:1319-25.

20 Ritter AJ, Fry C, Swan A. The ethics of reimbursing injecting drug users for public health research interviews: What price are we prepared to pay? Int J Drug Policy 2003;14:1-3.

21 Fry CL, Hall W. Key issues in determining the ethics of research subject payment: the special case of drug abuse epidemiology. Australas Epidemiologist 2003;10:41-7.

22 Lemmens T, Elliot $C$. Guinea pigs on the payroll: The ethics of paying research subjects. Accountability Res 1999;7:3-20.

23 Ackerman TF. An ethical framework for the practice of paying research subjects. IRB: A Review of Human Subjects Research 1989;11:1-4.

24 Macklin R. The paradoxical case of payment as benefit to research subjects. IRB: A Review of Human Subjects Research 1989;11:1-3. 